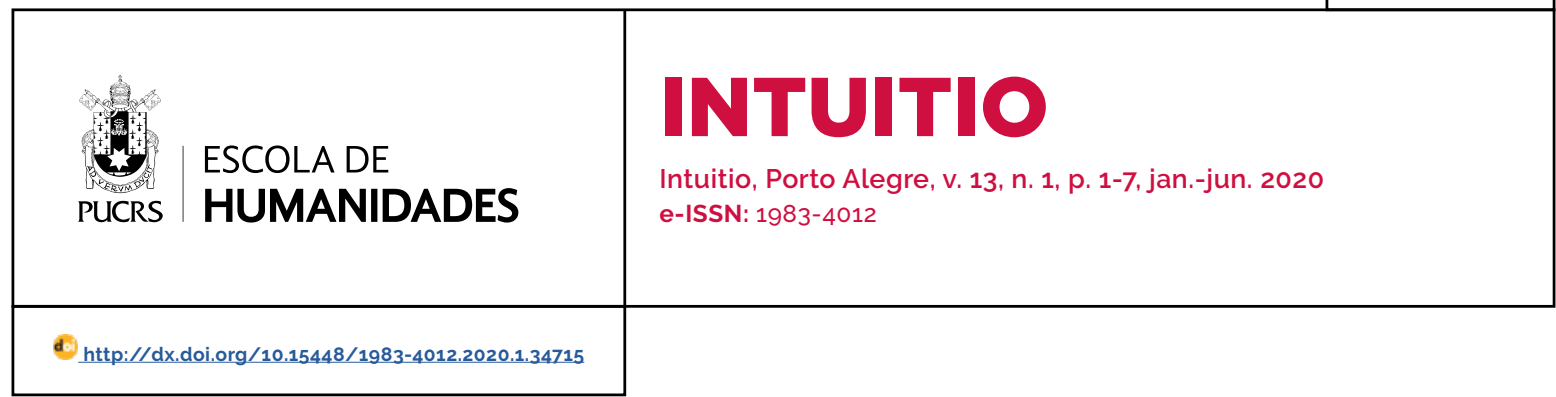

ARTIGO

\title{
Universais existem? Uma análise a partir da Teoria da Percepção de Searle
}

\author{
Are there universals? Revisiting the question through Searle's Theory of Perception
}

\author{
José Carlos Camillo \\ Castro Neto ${ }^{1}$ \\ orcid.org/0000-0002-4110-3386 \\ josecarloscamillo@gmail.com
}

Recebido em: 03 jul. 2019.

Aprovado em: 01 ago. 2019.

Publicado em: 27 jul. 2020.

\begin{abstract}
Resumo: Este artigo tem como objetivo revisitar a questão da existência dos universais. Essa questão foi muito debatida na Filosofia Medieval pelos nominalistas e realistas, especialmente influenciados pela leitura de Aristóteles. A questão também levantou debate na filosofia analítica e foi discutida por Strawson e Quine, além de lembrada por Searle. Neste trabalho, será investigado se os universais existem e em que qualidade de existência se encaixam tendo como principal pano de fundo a teoria da percepção de John Searle. Contudo, para isso, o assunto será analisado em seu contexto na filosofia contemporânea. Por isso, será exposta a definição strawsoniana de universais. Depois, será discutida a proposta do comprometimento ontológico de Quine e as criticas que recebeu de Searle. Construido esse cenário, será apresentada a teoria da percepção de Searle e, então, serão discutidas as consequências de tal teoria para um estudo ontológico dos universais. Conclui-se neste trabalho que a teoria da percepção consegue explicar bem a formação de conteúdo Intencional através do objeto e que, portanto, o universal como parte do objeto, tendo características no mundo físico, deve existir como entidade não-linguística.

Palavras-chave: Universais. Ontologia. Comprometimento Ontológico. John Searle. Percepção.
\end{abstract}

Abstract: This paper revisits the old question about the ontology of universals. It was extensively debated in Medieval Philosophy, especially by the influence of Aristotle's writings. That question was also discussed by Strawson and Quine in the twentieth century. This paper aims to investigate the existence of universals and the quality of its existence. The background for this research was the theory of perception of John Searle. However, in order to reach this goal, it will be showed and discussed some previous theories about the ontology of universals, such as the proposals of Strawson and Quine. From Strawson, it will be analyzed his definition of universals. From Quine, it will be discussed the famous proposal of the ontological commitment. The research built from this scenario and, then, exposed the theory of perception of John Searle. Only then, the consequences of that theory to the study of the ontology of universals were analyzed. As a matter of conclusion, it will be realized that the theory of perception of Searle points to the existence of the universals as non-linguistic entities whose characteristics remain present in the real world.

Key-words: Universals. Ontology. Ontological Commitment. John Searle. Perception.

\section{Introdução}

A questão da existência dos universais está presente na filosofia, pelo menos, desde Platão e Aristóteles. Desde então, especialmente na Idade Média, o tópico foi ganhando maior importância e sendo ainda mais desenvolvido.

Duas propostas filosóficas ganharam destaque ao tentar responder à questão da existência dos universais. A primeira, o nominalismo, propunha que eles não existiam a não ser no nome. A segunda proposta, o realismo, defendia que existiam fora da linguagem. 
Essa questão permanece na filosofia analítica, sendo debatida especialmente por Quine eStrawson com mais afinco, e está ligada especialmente ao funcionamento e conteúdo semântico de uma predicação. Segundo Strawson², apenas universais podem ser utilizados como predicados. Sua nãoexistência poderia comprometer o significado das predicações, já que o significado pressupõe uma relação palavra-mundo. Se não existe uma relação palavra-mundo no predicado, então ele ficaria deficiente de sentido.

Antes de abordar a questão da existência de universais, é necessário lidar com seu significado. Strawson ${ }^{3}$ apresentou duas condições necessárias para diferenciar um universal de um particular e propôs uma condição que poderia ser suficiente para tal. Segundo ele, uma condição necessária para que algo seja uma coisa geral (universal) é que ela pode ser referida através de uma única expressão substantiva, da qual a referência é tirada dos significados das palavras que compõem a expressão. A condição necessária para que algo seja particular é que não pode ser referida por meio de uma única expressão substantiva em que a referência é tirada dos significados das palavras que compõem a expressão.

O próprio Strawson reconhece, contudo, que essas condições não são suficientes para que algo se defina como universal ou particular. Para ele, a chave para essa diferenciação está na instanciabilidade. Apenas um universal pode ser instanciado enquanto um particular, jamais. Desse modo, um universal é uma "coisa", segundo a definição strawsoniana, que pode ser referida através de uma única expressão subjetiva e que pode ser instanciada através de particulares.

A partir dessa definição, ele classifica vários tipos de universais, como características, classes, números, propriedades, tipos e fatos/proposições. Contudo, antes de entrarmos no tema principal deste trabalho (ontologia dos universais) é necessário lidar com a questão de como seria possivel falar sobre eles. Esse ponto está presente no conceito de comprometimento ontológico de Quine.

\section{Comprometimento Ontológico de Quine}

A questão da existência dos universais também incomodou Quine. Ele propôs seu famoso conceito de comprometimento ontológico justamente em resposta a esse tema. Em seu ensaio On what there is, ele começa abordando o assunto do título, que trata justamente da pergunta máxima da ontologia: o que existe? Ou: o que é aquilo que existe? Ambas as formulações geram as discussões no campo da ontologia. Nesse texto ${ }^{4}$, ele propõe que se use a teoria das descrições definidas para evitar questões relacionadas à existência de seres imaginados, como o Pegasus.

A partir de então, ele passa a tratar da existência de universais. Ora, como a questão da existência do Pegasus pode ser evitada através da utilização de descrições definidas, Quine ${ }^{5}$, então, preocupase em como utilizar uma linguagem que, de fato, trate da existência de universais. Isso porque esse ponto the parece de somenos importância, como se todos concordassem quanto a seu caráter ontológico (Pegasus não existe), enquanto a existência dos universais seria, de fato, uma questão sobre existência. Por isso, o que o autor tenta apresentar com Pegasus é como falar dele sem se comprometer com sua existência, enquanto o que tenta apresentar com os universais é como falar deles e se comprometer com sua existência.

Segundo ele, para se envolver com a existência de algo, o que chama de comprometimento ontológico, deve-se levar em conta uma teoria porque a sua única forma é através do uso de variáveis. E uma entidade seria, então, reconhecida como o valor de uma variável. Desse modo, uma pessoa só está comprometida com a existência de algo se, e somente se, esse algo pode ser reconhecido entre as entidades dentro da gama de variáveis dessa pessoa de modo que as afirmações dela sejam verdadeiras. ${ }^{6}$

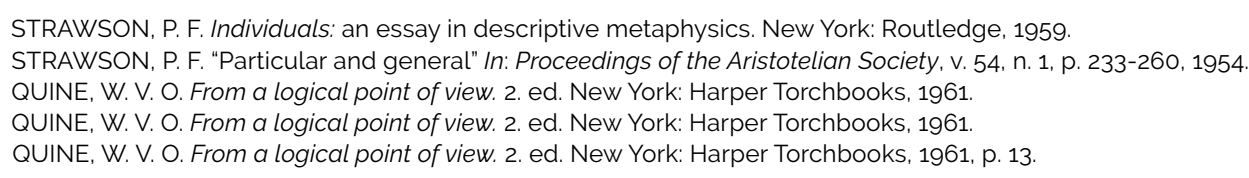


Quine reconhece, contudo, que esse método não é capaz de dizer o que existe, mas o que uma teoria diz que existe, "Mas o que há é outra questão".7 Desse modo, conclui afirmando que a questão acerca de qual teoria escolher permanece aberta e deve ser abordada com tolerância e espirito experimental.

O autor apresentou esse conceito de comprometimento ontológico justamente porque não consegue expor uma defesa da existência ou não dos universais. Contudo, segundo ele, isso não deveria impedir a filosofia de tratar do assunto. Em outro ensaio, Logic and the reification of universals ${ }^{8}$, esclarece melhor a questão, propondo que, enquanto uma teoria que defenda a existência de universais deva utilizar uma linguagem que tenha comprometimento ontológico, pressupostos que negam ou são indiferentes à sua existência podem tratar deles sem se comprometerem ontologicamente.

Segundo o teórico, a linguagem ideal para que haja comprometimento ontológico é a da quantificação. Nessa linguagem, em ", o x é uma variável que funcionaria como um pronome. Como num texto em que um pronome retoma algo anterior, $x$ retomaria uma gama de entidades que se encaixaria, no mundo real, à expressão 'algum x'. Essa gama de entidades seria chamada de gama de valores de uma variável. Além da linguagem quantificacional, é necessário, segundo ele, que cada entidade de uma teoria tenha identidade. A teoria de identidade apresentada por Quine é a dos conjuntos, um pouco modificada da de Zermelo-Frankel, em que um elemento do conjunto deve ser idêntico a si mesmo.

Desse modo, entidades são adotadas por uma perspectiva se e somente se elas podem ser contadas como estando entre os valores de uma variável de modo que as afirmações na teoria sejam verdadeiras. De novo, Quine ${ }^{9}$ reitera que não está indicando uma dependência do ser à linguagem porque não está considerando o estado ontológico das coisas, mas o comprometimento ontológico de um discurso. Assim, em temas polêmicos sobre ontologia também é possivel abordar um tema sem que se comprometa com a existência do objeto em questão. É o caso da existência de universais.

Ele apresenta ainda melhor o funcionamento de uma abordagem aos universais que não se comprometa ontologicamente em Word and Object. Segundo Quine ${ }^{10}$, para que isso aconteça, é necessário parafrasear as afirmações acerca do assunto no que ele chama de linguagem canônica (conforme descrita acima: linguagem quantificacional e teoria de identidade) sem que se utilize comprometimento ontológico. Desse modo, quando dizemos "existem onze quilômetros entre a Universidade Federal do Mato Grosso e a Arena Pantanal", a expressão parece nos comprometer com a existência de quilômetros, mas, segundo Quine, esse comprometimento pode ser anulado se parafrasearmos essa sentença em "distânciaem-quilômetros da UFMT à Arena Pantanal=11". Em linguagem formal:

$(\exists x)(\exists y)(x$ é 11 e $y$ é Arena Pantanal e $x$ é a distância em quilometros partindo da UFMT).

Assim, de acordo com Quine, um aparente comprometimento ontológico não passa de uma inadequação da linguagem. Contudo, Searle ${ }^{11}$, critica essa posição. Para ele, essa abordagem perde de vista que o que importa numa afirmação é o que está sendo dito e não como está sendo dito. Além disso, Searle demonstra que esse critério de comprometimento ontológico leva a uma contradição.

Segundo Searle, uma pessoa pode se comprometer com qualquer coisa conforme o critério quineano. Um exemplo que ele dá é afirmar a existência de todo conhecimento científico (vamos abreviar para C) comprometendo-se

\footnotetext{
7 No original: "But what there is is another question." In: QUINE, W. V. O. From a logical point of view. 2. ed. New York: Harper Torchbooks 1961, p. 16.

8 QUINE, W. V. O. From a logical point of view. 2. ed. New York: Harper Torchbooks, 1961, p. 103.

9 QUINE, W. V. O. From a logical point of view. 2. ed. New York: Harper Torchbooks, 1961, p. 103.

10 QUINE, W. V. O. Word and object. 2. ed. Cambridge: MIT Press, 2013.

11 SEARLE, John R. Speech Acts: an essay in the philosophy of language. New York: Cambridge University Press, 1969.
} 
apenas com a existência de uma caneta (vamos considerar a preposição P como sendo a de que existe essa caneta) no exemplo a seguir:

\author{
1. Essa caneta $=$ essa caneta $($ axioma $)$ \\ 2. C (axioma) \\ 3. Essa caneta $=$ essa caneta $\cdot C$ \\ 4.P (essa caneta) \\ 5. $\exists x(P x)^{12}$
}

Nesse caso, 2 e 3 comprometem-se com a existência de todo o conhecimento científico, o que vai muito além da existência dessa caneta, mas minha preposição $\mathrm{P}$ (4), que assume (3) todo o conhecimento científico, envolve-se apenas com a existência da caneta (5). Ou seja, 4 assume 2 e 3 mas não com eles. Isso é uma contradição de termos e, por isso, Searle recomenda que tal critério seja desconsiderado como válido para o comprometimento ontológico.

A sugestão do próprio Searle ${ }^{12}$ é que não há uma classe irredutivel de comprometimento ontológico. Ao contrário, qualquer frase com sentido existencial pode ser expressa ou reformulada em outra. Desse modo, o comprometimento ontológico não está na forma como é dito, mas no conteúdo Intencional do que foi dito.

No caso dos quilômetros entre a UFMT e a Arena Pantanal, tanto a frase por extenso quanto a mesma em linguagem formal estão comprometidas com a existência de quilômetros. Nesse caso, eles existem ou não?

\section{A Proposta Inicial de John R. Searle}

Searle responde à pergunta "os universais existem?" inicialmente com "de certa forma, sim". Segundo ele, se dissermos que universais existem como fatos do mundo, estamos enganados. Mas, se dissermos que eles existem como significados, entidades linguísticas, estamos corretos. A negação dos nominalistas de que existe uma propriedade tal como o vermelho está equivocada porque essa propriedade existe, mas apenas como entidade linguística. ${ }^{13}$ E como isso ele não quer dizer que universais são como palavras, mas que são como os significados delas.

Para demonstrar isso, ele se propõe a diferenciar a identificação de um universal numa predicação da identificação de um objeto numa referência. Nesse último caso, identifica-se o referente ao transmitir ao ouvinte um fato acerca do objeto. No primeiro caso, identifica-se o predicado através da relação entre palavras (como em "o livro e a rosa são da mesma cor") e seu significado ou através de demonstrativos (como em "o livro é daquela cor").

Assim, o modo de identificação de um particular é diferente do modo de identificação de um universal porque este é parte de nosso modo de descrever o mundo e não uma parte do mundo, como o é o particular. Por isso, ele diz que "[...] nós podemos dizer que universais não são identificados via fatos, mas via significados".14

Além disso, Searle continua argumentando que derivamos um universal de seu predicativo. Por exemplo, derivamos "generosidade" de "generoso". Desse modo, é possivel perceber que "generosidade" não é algo que percebemos do mundo, mas algo que construímos ao relacionar coisas que percebemos do mundo, por ser derivada.

Ainda mais, segundo ele, poderiamos imaginar uma linguagem que só tenha particulares e expressões predicativas (do tipo "é generoso"), mas não uma que tenha apenas particulares e expressões para se referir a propriedades. Como exemplo da linguagem que podemos imaginar, ele usa o termo particular "Sócrates" e a expressão predicativa "é sábio", bem como "esta rosa" e "é vermelha". Já para a linguagem que não podemos imaginar, ele usa os mesmos particulares "Sócrates" e "esta rosa" e as expressões para se referir a propriedades "sabedoria" e "vermelhidade". Essa impossibilidade evidenciaria que "generosidade" é derivado de "é generoso" e que, portanto, sendo derivado, não se percebe nos fatos do mundo, mas no modo como os apresentamos.

\footnotetext{
SEARLE, John R. Speech Acts: an essay in the philosophy of language. New York: Cambridge University Press, 1969, p. 111

SEARLE, John R. Speech Acts: an essay in the philosophy of language. New York: Cambridge University Press, 1969, p. 105.

No original: "[...] we might say that universals are not identified via facts, but via meanings" In: SEARLE, John R. Speech Acts: an essay in the philosophy of language. New York: Cambridge University Press, 1969, p. 116
} 
Por isso, conclui que nenhuma informação factual é exigida para identificar um universal. Portanto, "O axioma da identificação de universais requer somente que o falante saiba o significado do termo geral que está na base do termo singular abstrato usado para se referir ao universal".15

Porém, essa argumentação não se sustenta diante da própria teoria de Searle. Especialmente quando levamos em conta seu entendimento sobre referência. Para ele, as referências baseiam-se em dois axiomas: o axioma da existência (o que é referido deve existir) e o axioma da identidade (quando um predicado for verdadeiro acerca de um objeto, será verdadeiro acerca de um objeto idêntico a despeito da expressão que se utiliza para se referir a ele). A esses dois axiomas geralmente aceitos, o autor acrescenta o axioma da identificação (o falante deve ser capaz de identificar o objeto referido ao ouvinte). Esse axioma acrescentado parece bastante intuitivo, pois ajuda a evitar possiveis ambiguidades no ato de referir-se.

O primeiro e o terceiro axiomas produzem duas condições necessárias para que haja uma referência: (1) deve existir um e somente um objeto ao qual o enunciado se aplica e (2) o ouvinte deve ter meios suficientes para identificar o objeto a partir do enunciado do falante. Por isso, o enunciado numa referência ideal seria formado pelo que Searle chama de descrição de identificação, em que o próprio enunciado seria suficiente para identificar o objeto. ${ }^{16}$ Essa descrição poderia ser feita por meio de enunciados descritivos ou demonstrativos ou uma mistura dos dois.

Pela necessidade dessa descrição de identificação, ele percebe que para haver uma referência, o falante deve apontar conteúdos descritivos acerca do objeto. A esses conteúdos descritivos, Searle chama de significados. ${ }^{17}$ Por isso, conclui que o significado é anterior à referência e que esta ocorre em virtude do significado.

Diante disso, tornam-se confusas as afirmações de Searle: por um lado, identifica-se o predicado pelo significado e identifica-se o referente pelo significado; por outro lado, ele mesmo admite que uma referência também só acontece por meio de significados. Onde reside a diferença não fica claro. Ao contrário, fica mais obscuro o fato de que ambos são identificados por enunciados descritivos e/ou demonstrativos.

Por fim, seu argumento de que o substantivo de um universal deriva de um adjetivo pode ser bem questionado por linguistas. ${ }^{18}$ Sua ideia da impossibilidade de haver uma linguagem composta por particulares e universais substantivados, como "Sócrates" e "sabedoria" também esbarra em dados de línguas antigas, como o hebraico antigo.

Um exemplo é o exposto por Miller ${ }^{19}$ em que uma expressão no Pentateuco da Biblia Hebraica exibe: קידצה הוהי ("Senhor Justiça" em tradução direta, ou "O Senhor é justiça" ou ainda "o Senhor é justo"). Segundo ela, expressões como esta aparecem mais de duas mil vezes apenas nos cinco primeiros livros da Biblia Hebraica. A impossibilidade parece estar apenas na teoria.

Por causa disso, a crítica de Searle à qualidade ontológica dos universais precisa de argumentos mais claros ou ser revisada. Isso é o que vamos fazer analisando sua teoria da percepção, apresentada em 2015.

\section{Teoria da Percepção de Searle e Prováveis Consequências Ontológicas}

Para começar a analisar a percepção, Searle ${ }^{20}$ faz uma diferenciação. Segundo o autor, existem os perceptos básicos, como cor e forma, que são

\footnotetext{
15 No original: "The axiom of identification for universals requires only that the speaker know the meaning of the general term which underlies the abstract singular term used to refer to the universal" In: SEARLE, John R. Speech Acts: an essay in the philosophy of language. New York: Cambridge University Press, 1969, p. 121

16 Nos enunciados, numa fala cotidiana, não é necessária uma descrição de identificação bem definida porque o ouvinte apreende o objeto especifico pela fala e pelo contexto. Contudo, caso haja ambiguidade e o ouvinte fique sem saber ao quê o falante está se referindo para que a referência seja completa, o falante deve pronunciar um enunciado completo que permita a identificação sem ambiguidades. 17 SEARLE, John R. Speech Acts: an essay in the philosophy of language. New York: Cambridge University Press, 1969. p. 92.

${ }_{18} \mathrm{O}$ próprio hebraico antigo, mencionado mais à frente neste mesmo parágrafo, utiliza-se mais de substantivos que adjetivos para construir expressões predicativas.

19 MILLER, Cynthia L. "Pivotal issues in analyzing the verbless clause" In: MILLER, Cynthia L (ed.). The verbless clause in Biblical Hebrew: linguistic approaches. Winona Lake: Eisenbrauns, 1999

20 SEARLE, John R. Seeing things as they are: a theory of perception. New York: Oxford University Press, 2015
} 
percebidos de maneira imediata, e os derivados, que necessitam de conteúdo de um background mental para serem percebidos.

O exemplo que ele dá é da tridimensionalidade. A imagem formada na retina é claramente bidimensional, mas o cérebro promove uma experiência tridimensional com base nessa imagem e em conteúdos e características evolutivamente desenvolvidas que permitem uma percepção de mundo em três dimensões.

Searle, então, passa a defender que a percepção gera conteúdo Intencional. De modo simples, Intencionalidade, para ele, é a caracteristica de alguns eventos/estados mentais de ter uma direção para o mundo. ${ }^{21}$ A percepção gera, de algum modo, essa direção para o mundo. Segundo o autor, nem tudo da percepção é conteúdo Intencional, mas a percepção tem isso. $O$ conteúdo Intencional é formado por condições de satisfação e por um modo psicológico que indica a direcionalidade dessas condições de satisfação.

Por exemplo, a crença de que Cuiabá completa 300 anos de formação em 2019 se satisfará se esse for o caso. A direcionalidade, aqui, é mentemundo. A crença (estado Intencional) deve se adequar ao mundo para que as condições sejam satisfeitas. No caso de um desejo, como morar em Cuiabá, será satisfeita caso eu passe a morar naquela cidade. Assim, no desejo, o mundo deve se adequar ao estado Intencional para que as condições sejam satisfeitas.

No caso da percepção em especifico, como parte de suas condições de satisfação, está uma autorreferência causal.22 Ou seja, para que ela seja verídica, é necessário que o objeto percebido esteja causando a própria experiência perceptiva. Assim, de alguma forma, é o objeto que produz conteúdo Intencional na mente. E como funciona esse processo?

Searle ${ }^{23}$, antes de responder a essa pergunta, ressalta a importância de reconhecer que 0 sistema perceptivo humano foi desenvolvido de modo a captar caracteristicas da natureza.
Isso explica o porquê, segundo ele, é uma caracteristica da natureza que ela seja percebida conforme a percebemos. O exemplo que dá é o da percepção visual de uma maçã vermelha. Quando alguém vê uma maçã vermelha, sendo a cor e a forma perceptos básicos, é uma caracteristica da vermelhidade que ela produza a experiência de vermelho nos seres humanos.

O caso de daltônicos ou qualquer distúrbio perceptivo é de exceção porque seu sistema perceptivo está, de alguma forma, prejudicado e, portanto, não capta o vermelho com a experiência visual da cor. Imagine, no entanto, que um daltônico $X$, ao captar a vermelhidade, tenha experiência visual do azul. Assim, é uma caracteristica da vermelhidade que produza nesse daltônico $X$ a experiência visual do azul. Caso esse daltônico específico expresse de modo realista sua experiência visual em uma tela de tinta a óleo, por exemplo, ele utilizará a cor que ele viu como azul, que, no caso, é a mesma que a maioria enxerga como vermelho.

Parece evidente, a partir do que foi exposto acima, que Searle admite uma realidade não linguistica para os universais quando expressa caracteristicas que uma vermelhidade possua. Vermelhidade, sendo instanciada na maçã, é claramente um universal segundo a concepção que expomos no começo deste trabalho. Além disso, a vermelhidade, tendo caracteristicas discerniveis no mundo, está sendo apresentada com base em fatos do mundo por Searle e, portanto, está sendo objeto de uma referência.

Desse modo, o autor parece apontar para uma teoria não plantonista de universais, mas, talvez, aristotélica. Os universais existem no mundo e são percebidos pelo contato com vários exemplares deles. Não estão em algum plano ideal de existência, mas no mundo físico. E, ao contrário do exposto anteriormente, existem alguns universais que nós percebemos de maneira direta, enquanto outras caracteristicas, como tridimensionalidade, necessitam de um background mental para serem percebidas. 


\section{Considerações Finais}

Talvez Searle não concordasse com o que expus acima. Mas, ao menos, deveria deixar de descrever, para benefício de uma coerência teórica, os universais como entidades meramente linguísticas. Universais, como a cor, são a matéria básica da percepção para o autor e a sua percepção não é conteúdo linguístico, como o próprio Searle reitera ao longo desse livro em que trata da teoria da percepção. Portanto, podemos concluir, por meio da teoria da percepção esposada por ele, que os universais são entidades não-linguísticas e perceptos básicos (aspectos da natureza percebidos de forma direta por mentes conscientes).

Alguém poderia argumentar, contudo, que a teoria da percepção de Searle está equivocada. Isso, é claro, não é impossivel. Contudo ela tem grande poder explicativo ao exibir a formação de conteúdo Intencional por meio da percepção. Se entendemos Intencionalidade como a característica pela qual estados/eventos mentais se direcionam ao mundo, fica evidente que se forma por meio da percepção ou se direciona a ela.

Nesse caso, ou a percepção forma conteúdo Intencional independente do objeto, o que geraria dois problemas (um idealismo cego, em que tudo o que percebemos é produto de nossa mente e uma incongruência com pressupostos científicos e fenomenológicos - o que produziria um ceticismo acerca da percepção), ou a percepção forma conteúdo Intencional dependente do objeto. Neste segundo caso, que parece o mais provável, o objeto produziria conteúdo Intencional através da percepção.

De qualquer forma, se formos lidar com a questão da existência dos universais, tendo a teoria searleana da percepção como pressuposto, concluiremos que universais existem como entidades não-linguísticas independentemente da forma de enunciação que utilizarmos para expressar tal ideia. Isso por que há comprometimento ontológico dessa teoria mesmo que ela não utilize uma linguagem canônica.

Há, portanto, uma conexão entre teoria da percepção e ontologia dos universais que pode ser melhor abordada em trabalhos futuros. Este trabalho, portanto, não fecha o assunto abordado, mas apresenta novas possibilidades de lidar com o mesmo.

\section{REFERÊNCIAS}

MILLER, Cynthia L. Pivotal issues in analyzing the verbless clause. In: MILLER, Cynthia $L$ (ed.). The verbless clause in Biblical Hebrew: linguistic approaches. Winona Lake: Eisenbrauns, 1999.

QUINE, W. V. O. From a logical point of view. 2. ed. New York: Harper Torchbooks, 1961

QUINE, W. V. O. Word and object. 2. ed. Cambridge: MIT Press, 2013. https://doi.org/10.7551/mitpress/9636.001.0001.

SEARLE, John R. Speech Acts: an essay in the philosophy of language. New York: Cambridge University Press, 1969. https://doi.org/10.1017/CBO9781139173438.

SEARLE, John R. Intentionality: an essay in the philosophy of mind. New York: Cambridge University Press, 1983. https://doi.org/10.1017/CBO9781139173452.

SEARLE, John R. Seeing things as they are: a theory of perception. New York: Oxford University Press, 2015. https:// doi.org/10.1093/acprof:0so/9780199385157.001.0001.

STRAWSON, P. F. Particular and general. Proceedings of the Aristotelian Society, v. 54, n. 1, p. 233-260, 1954. https://doi.org/10.1093/aristotelian/54.1.233.

STRAWSON, P. F. Individuals: an essay in descriptive metaphysics. New York: Routledge, 1959.

\section{José Carlos Camillo Castro Neto}

Mestrando em Filosofia pelo Programa de Pós- Graduação em Filosofia da Universidade Federal de Mato Grosso (UFMT, Cuiabá, MT, Brasil), bolsista da Coordenação de Aperfeiçoamento de Pessoal de Nivel Superior (Capes)

\section{Endereço para correspondência:}

José Carlos Camillo Castro Neto

Universidade Federal do Mato Grosso

R. Quarenta e Nove, 2367

Boa Esperança 78060-900

Cuiabá, MT, Brasil 